\title{
A economia criativa como proposta de valor nos modelos de negócio
}

\begin{abstract}
RESUMO
A economia criativa foca no potencial individual ou coletivo para produzir bens e serviços criativos. Em particular, nas atividades baseadas no conhecimento e que produzem bens tangíveis e intangíveis, intelectuais e artísticos, com conteúdo criativo e valor econômico. Assim, os modelos de negócio ou gestão originam-se de atividades, produtos ou serviços desenvolvidos a partir do conhecimento, criatividade ou capital intelectual de indivíduos, com vistas à geração de trabalho e renda. $\mathrm{O}$ artigo apresenta uma pesquisa exploratória bibliográfica sistemática sobre economia criativa, indústria criativa e bens e serviços criativos no Brasil, bem como a relação entre o conceito de quadro de modelo de negócios e as novas formas de negócio da economia criativa. Traz argumentações e reflexões sobre a necessidade de planejamento, pesquisa e inovação, para se conseguir uma atitude proativa no negócio e, assim, fazer frente às mudanças e transições do sistema produtivo.
\end{abstract}

Palavras-chave: Economia criativa. Quadro de proposta de valor. Modelo de negócio. Design thinking.

Francisco Gómez Castro

Doutorando em Design Universidade Federal de Santa Catarina (UFSC) - Brasil

francisco.gomez.castro1@gmail.com

Luiz Fernando Figueiredo

Doutor em Engenharia de Produção Universidade Federal de Santa Catarina (UFSC) - Brasil

Iff@cce.ufsc.br 


\section{INTRODUÇÃO}

Procurando conhecer o estado da economia criativa no Brasil, assim como o grau de desenvolvimento da indústria criativa, das tipologias de bens e serviços criativos no país, e a relação entre o conceito de quadro de modelo de negócios e as novas formas de negócio da economia criativa, este artigo tem o objetivo de refletir sobre a necessidade do planejamento, da pesquisa e da inovação, na busca de conseguir uma atitude proativa no negócio, baseada nos fundamentos da economia criativa, para que se possa fazer frente as mudanças e transições do sistema produtivo.

\section{REFERENCIAL TEÓRICO}

Esta seção apresenta uma revisão da literatura dos tópicos relevantes para este trabalho: 1 - economia criativa, indústrias criativas e sua abordagem no Brasil, e 2 - modelo de negócios em transição e quadro de proposta de valor.

\subsection{Economia criativa, indústrias criativas e sua abordagem no Brasil}

A relevância do conceito de economia criativa se dá a partir da década de 2000, embora seu nascimento tenha ocorrido depois da crise dos anos 1970. Ainda hoje, apresenta diferentes definições e formas de mensuração e caracterização. Howkins (2002) sustenta a ideia de que a economia criativa se assenta sobre a relação entre a criatividade, o simbólico e a economia.

Oliveira, Araujo e Silva (2013), em suas análises do panorama da economia criativa no Brasil, definem-na como o conjunto de atividades econômicas que dependem do conteúdo simbólico, incluído aí a criatividade como fator mais expressivo para a produção de bens e serviços. Dessa forma, permitem caracterizar economia criativa como uma disciplina distinta da economia da cultura, que guarda grande relação com aspectos econômicos, culturais e sociais que interagem com a tecnologia e a propriedade intelectual em uma mesma dimensão e tem relações de transbordamento muito próximas ao turismo e ao esporte.

Por outro lado, o Serviço Brasileiro de Apoio às Micro e Pequenas Empresas (SEBRAE, 2015) entende o conceito como um termo criado para nomear modelos de negócio ou gestão que se originam em atividades, produtos ou serviços desenvolvidos a partir do conhecimento, criatividade ou capital intelectual de indivíduos com vistas à geração de trabalho e renda, focando no potencial individual ou coletivo para produzir bens e serviços criativos. Nesse sentido, a Organização das Nações Unidas (ONU) refere-se àquelas atividades baseadas no conhecimento e que produzem bens tangíveis e intangíveis, intelectuais e artísticos, com conteúdo criativo e valor econômico (VICKERY, 2013).

Nessa mesma linha, o Ministério da Cultura diz que a nova economia possui dinâmica própria e, por isso, desconcerta os modelos e coloca o conceito como a economia do intangível, do simbólico (BRASIL, 2011). Alimenta-se dos talentos criativos, que se organizam individual ou coletivamente para produzir bens e serviços criativos. Por se caracterizar pela abundância e não pela escassez, seus modelos de negócio ainda se encontram em construção, carecendo de marcos legais e de bases conceituais consentâneas com os novos tempos.

O conceito de economia criativa teve origem no termo indústria criativa, que, por sua vez, foi inspirado em um projeto conduzido pelo governo australiano, chamado Creative Nation, de 1994 (REIS, 2008). Esse projeto tinha como grandes objetivos definir a importância do trabalho criativo, identificar a sua contribuição para a economia australiana e definir o papel das tecnologias como aliadas da política cultural, abrindo espaço para novos setores no rol das indústrias consideradas criativas. Em 1997, o governo do Reino Unido se apercebeu da necessidade de analisar as contas nacionais, as tendências de mercado e as vantagens competitivas que o país poderia ter. Nesse exercício, foram identificados treze setores de maior potencial, as chamadas indústrias criativas. Esses conceitos rapidamente se espalharam por Cingapura, Líbano e Colômbia e de lá para o mundo. Segundo Buettgen e Freder (2015), as indústrias criativas são a atividade empresarial que gera valor econômico através de conteúdo de origem cultural. E, assim, para o autor, consegue unir os talentos da cultura empresarial clássica com os novos talentos originários do meio cultural, da mídia e da comunicação.

Os sistemas de classificação para as indústrias criativas podem estar sujeitos a adequações de um país para outro, mas são baseados na classificação feita pela Conferência das Nações Unidas sobre Comércio e Desenvolvimento (2010). Essa classificação das indústrias criativas é derivada dos diferentes modelos expostos no mesmo documento, que são: modelo do DCMS, modelo de textos simbólicos, modelo de círculos concêntricos e modelo de direitos autorais da OMPI.

No caso do Brasil, o último mapeamento da indústria criativa foi feito pela Federação das Indústrias do Rio 
Francisco Gómez Castro; Luiz Fernando Figueiredo

de Janeiro (FIRJAN, 2014). Nesse mesmo documento, entre outras informações, a FIRJAN fez um levantamento detalhado da cadeia produtiva, no qual apresenta quatro categorias ou áreas criativas que agrupam todos os segmentos ligados à indústria criativa. Essas quatro categorias ou áreas criativas são: consumo, cultura, mídias e tecnologia, colocando, no caso do consumo, os segmentos: publicidade, arquitetura, design e moda. Na categoria de cultura, considera os segmentos: expressões culturais, patrimônio e artes, música e artes cênicas. Enquanto que, na categoria mídias, os segmentos editorial e audiovisual. Por último, na categoria tecnologia, considera os segmentos: pesquisa e desenvolvimento (P\&D), biotecnologia e tecnologias da informação e da comunicação (TIC). As atividades que são agrupadas em cada um dos segmentos, assim como as atividades relacionadas a essas e o apoio dos ofertantes são mostradas na Figura 1.

Figura 1 - Fluxograma da Cadeia da Indústria Criativa no Brasil
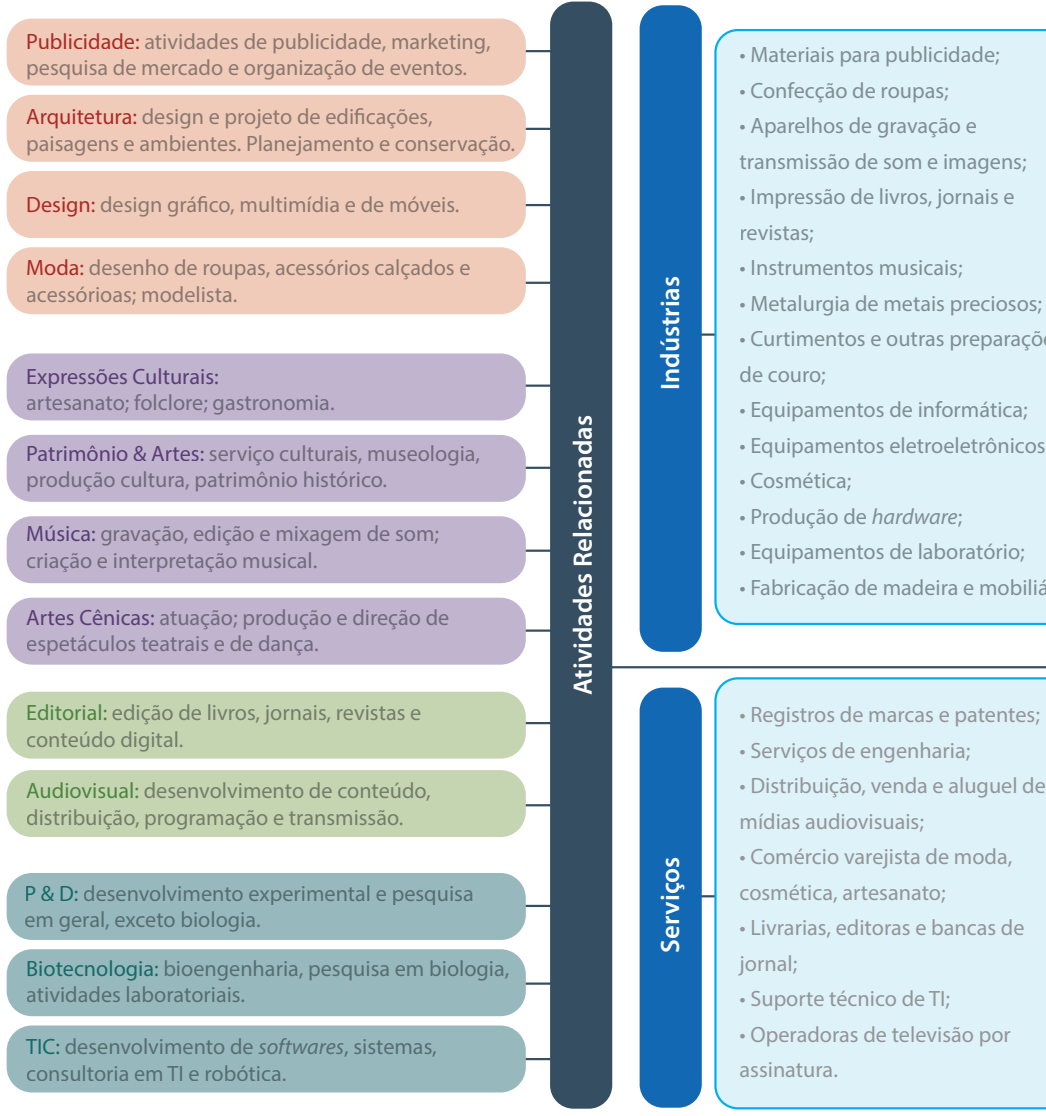

Fonte: FIRJAN (2014, p. 9)

O fluxograma da cadeia da indústria criativa no Brasil (Figura 1), organiza os conceitos acima expostos. O conceito de Indústria Criativa (Núcleo) é definido como aquele que é formado pelas atividades profissionais e/ou econômicas que têm as ideias como insumo principal para geração de valor. Enquanto que as atividades relacionadas, referem-se aos profissionais e estabelecimentos que provêm diretamente bens e serviços à Indústria Criativa. Esses são representados em grande parte por indústrias, empresas de serviços e profissionais fornecedores de materiais e elementos fundamentais para o funcionamento do núcleo criativo. $\mathrm{O}$ termo apoio refere-se aos ofertantes de bens e serviços de forma indireta à Indústria Criativa. Assim, segundo a FIRJAN (2014), a indústria criativa formada por todos esses elementos apresenta uma estimativa da participação do PIB Criativo em relação ao PIB Total (2004-2013), que passa de um 2,09\%, em 2004, para 2,60\%, em 2013.

Entretanto, o SEBRAE (2012) considera como características e potencialidades da economia criativa: a produção não poluente, a inovação tecnológica, o fortalecimento dos vínculos das características regionais e locais, a geração de emprego, renda e tributos, a estimulação de novas qualificações profissionais, a alimentação da economia associada a outros segmentos produtivos, a promoção da inclusão social, o reforço da cidadania e a promoção da diversidade e do respeito. Considera, também, como os quatro princípios norteadores da economia criativa: (i) a importância da diversidade cultural do país; (ii) a percepção da sustentabilidade como fator de desenvolvimento local e regional; (iii) a inovação como vetor de desenvolvimento da cultura e das expressões de vanguarda; e (iv) a inclusão produtiva com base em uma economia cooperativa e solidária (Figura 2). 
Figura 2 - Os quatro princípios norteadores da economia criativa

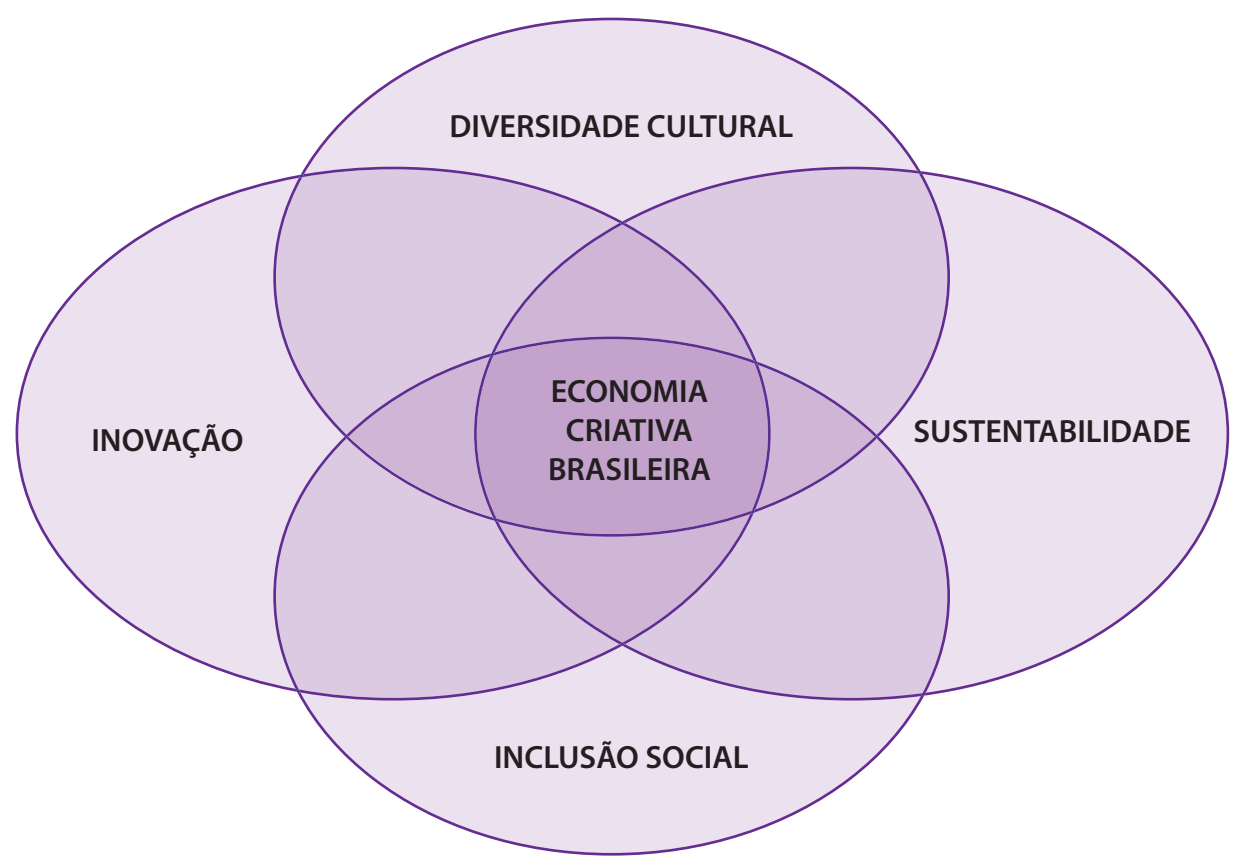

Fonte: SEBRAE (2012)

Os três eixos estratégicos de atuação na economia criativa fomentados pelo SEBRAE (2012) são: (i) o desenvolvimento setorial das atividades que compõem os segmentos da economia criativa; (ii) o desenvolvimento territorial estimulando a valorização das redes, dos costumes, da tradição e a vocação do local; (iii) o desenvolvimento transversal, levando componentes da economia criativa a todos os segmentos e setores da economia, de forma a gerar valor, diferenciais e estimular a competitividade das empresas.

Entretanto e apesar do anteriormente exposto, o SEBRAE (2012) coloca a necessidade de tornar os negócios sustentáveis, posto que os agentes que atuam no mercado dos negócios criativos no Brasil ainda precisam desenvolver a sustentabilidade de seus empreendimentos, adquirir independência dos recursos do Estado, profissionalizar a gestão e buscar a longevidade de seus negócios. Pelo que resulta imperioso, portanto, estimular modelos inovadores para o desenvolvimento da economia criativa brasileira.

\subsection{Modelo de negócios em transição e quadro de proposta de valor}

Alguns dos elementos e conceitos para entender o contexto da contemporaneidade e seu imaginário são: informacionalismo (CASTELLS, 2006), imaterialidade (GORZ; IMATERIAL, 2005), flexibilidade (HARVEY; SOBRAL, 1994), multiplicidade e virtuosismo (VIRNO, 2001), nomadismo (MAFFESOLI, 2001), etc. Geram um ambiente conformado e que também é conformador de estilos de vida alternativos associados à ética do trabalho fordista, num período pós-fordista. Considerando-se que há transição dos sistemas que ainda se encontram em andamento em todo o mundo, podíamos facilmente detectar a existência de modelos produtivos diversos convivendo no tempo e no espaço.

Por conta dessa complexidade, restringimo-nos ao recorte propiciado pela ênfase nas transformações ocorridas ao redor da relação sujeito/trabalho, em particular as decorrentes da passagem da materialidade do industrialismo à imaterialidade do informacionalismo. Tudo isso para vislumbrarmos, mesmo que de forma simplificada e incompleta, parte do novo espírito do capitalismo em andamento (BOLTANSKI; CHIAPELLO, 2002).

Em ambientes instáveis e carregados de incerteza, modelos de negócios bem projetados e inovadores podem desempenhar papel crucial, realizando a ligação entre estratégia, processos internos e sistemas de informação, simplificando a comunicação entre esses componentes e favorecendo a difusão do conhecimento interno, o que por sua vez acaba gerando vantagem competitiva (OSTERWALDER, 2004). Osterwalder e Pigneur (2010) descrevem o ciclo de desenvolvimento de um modelo de negócios como a maneira como uma organização cria, entrega e captura valor. Posto que as empresas de economia criativa estão inseridas no terceiro setor. Segundo Miguez (2007), a economia criativa trata dos bens e serviços, baseados em símbolos 
e imagens, e refere-se ao conjunto de atividades fundamentadas na criatividade ou mesmo na habilidade individual cognitiva e cujos produtos incorporam propriedade intelectual, abrangendo as complexas cadeias produtivas culturais.

Assim, a proposta de valor, segundo Osterwalder e Pigneur (2010), procura resolver os problemas do cliente e satisfazer suas necessidades e cada proposta de valor cria valor para um segmento de cliente com uma combinação de elementos direcionados especificamente àquele segmento. $O$ segmento (ou os segmentos) de clientes define os diferentes grupos de pessoas ou organizações que uma empresa busca alcançar e servir. De modo que a proposta de valor consiste em um conjunto selecionado de produtos e/ou serviços que satisfaz as exigências de um segmento de clientes específico. Por tudo isso, precisamos saber que valor entregamos ao cliente, quais são os problemas que estamos ajudando a resolver, que necessidades estamos satisfazendo e que conjunto de produtos e serviços estamos oferecendo para cada segmento de cliente. O quadro de proposta de valor (OSTERWALDER et al, 2015), aprofunda essa análise, já que busca encaixar o valor que uma empresa cria a partir da observação de seus clientes (Figura 4). Para isso, a proposta de valor se divide em duas partes: perfil do cliente e mapa de valor.

O perfil do cliente refere-se a um segmento de cliente específico e o mapa de valor aos aspectos de uma proposta de valor específica criada por uma empresa.

O perfil do cliente, por sua vez, é dividido em três blocos: tarefas do cliente, dores e ganhos. Onde as tarefas do cliente são aquilo que os clientes de determinado segmento estão tentando fazer. As dores abordam os resultados ruins, os riscos e os obstáculos relativos às tarefas do cliente. E, por último, o bloco de ganhos descreve os resultados que os clientes querem alcançar ou os benefícios concretos que estão procurando.

Já o mapa de valor contém três blocos: produtos e serviços, analgésicos e criadores de ganhos. O bloco de produtos e serviços lista todos os produtos e serviços em torno dos quais uma proposta de valor é construída. O bloco dos analgésicos descreve como os produtos e/ou serviços aliviam a dor do cliente e o dos criadores de ganhos refere-se a como os produtos e/ou serviços criam ganhos para o cliente.

Figura 3 - Quadro do Modelo de Negócio

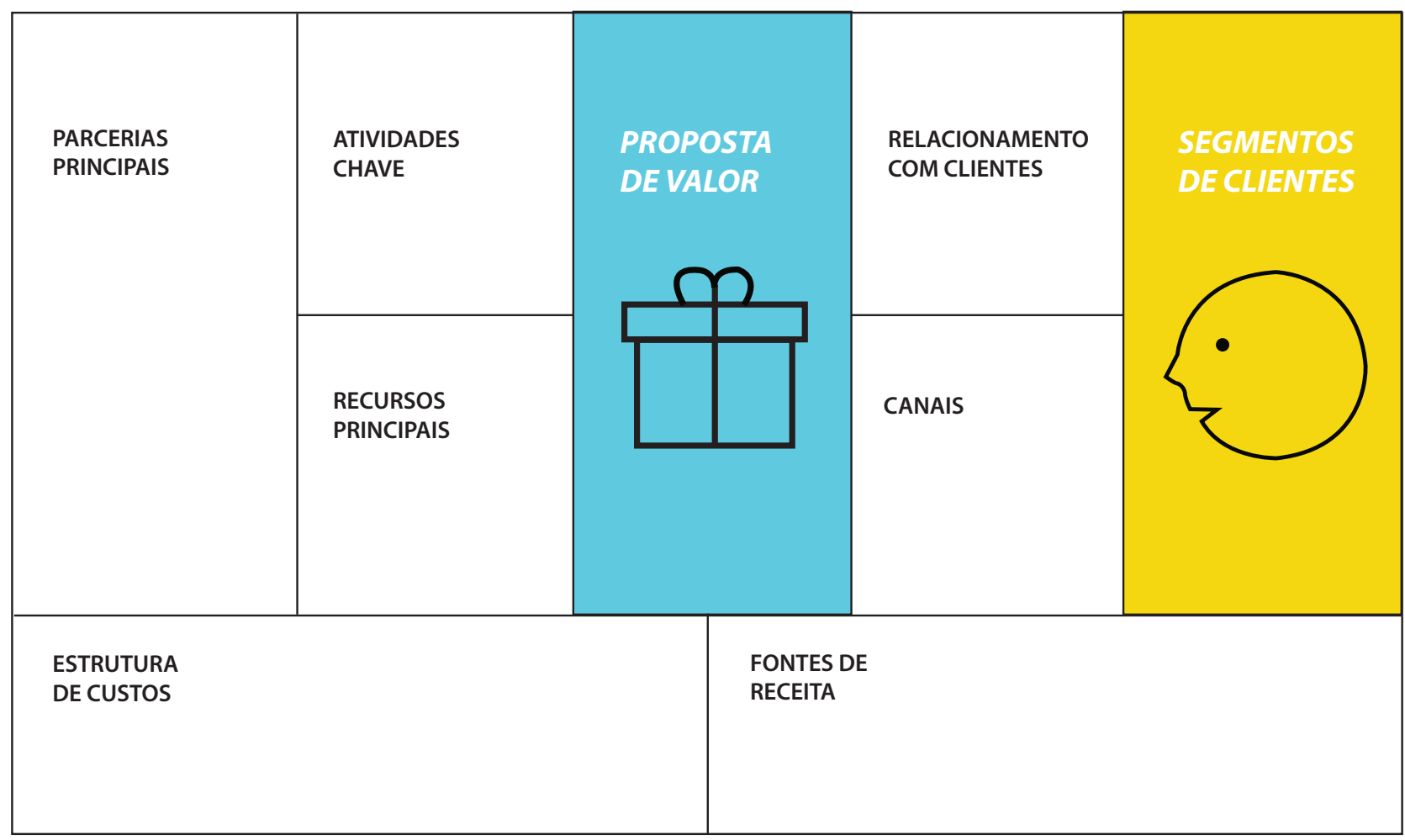

Fonte: Osterwalder e Pigneur (2010) 


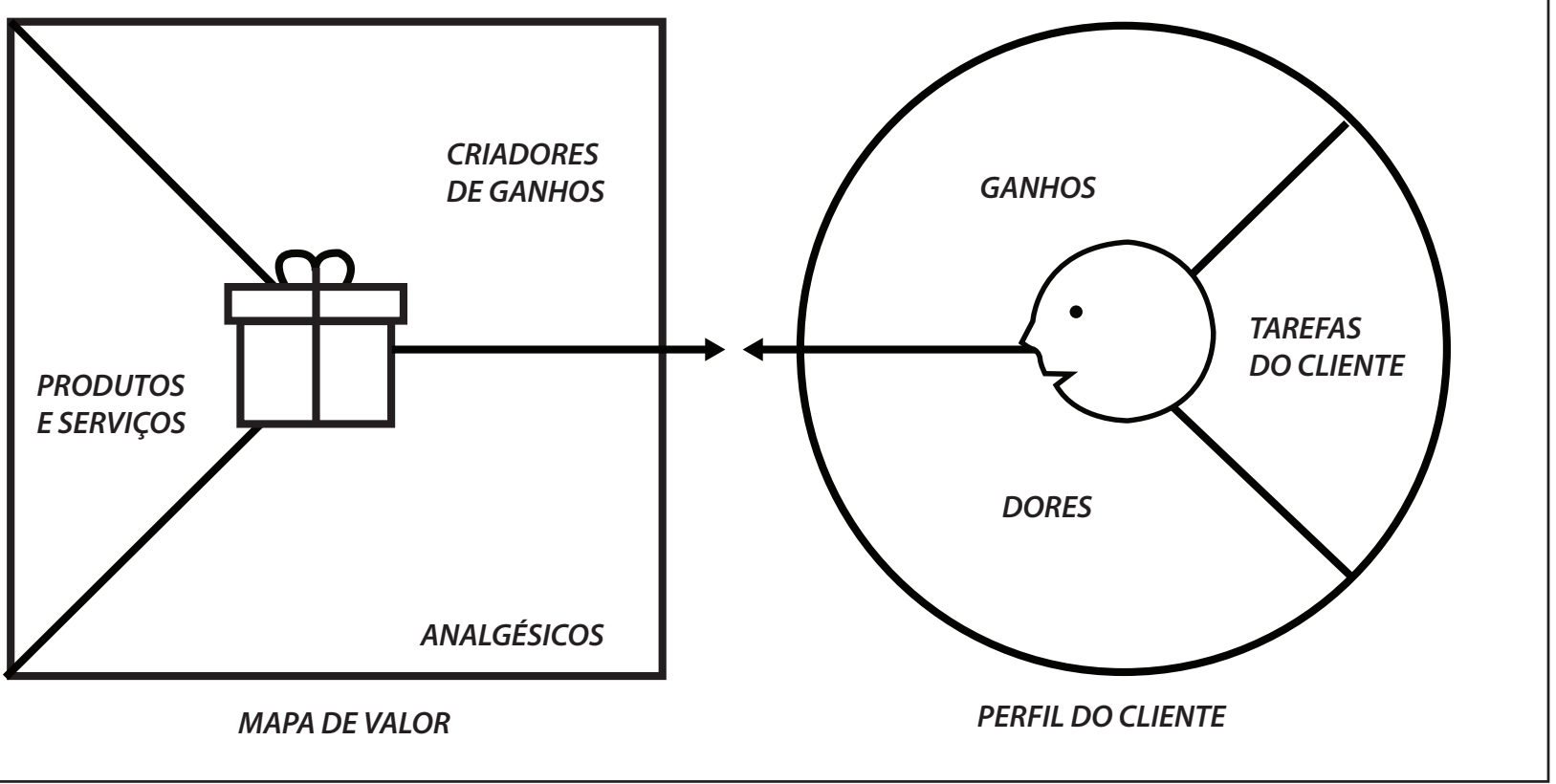

Fonte: Osterwalder e Pigneur (2015)

\section{PROCEDIMENTOS METODOLÓGICOS}

Como metodologia, tem-se por base a taxonomia proposta por Gil (2002) e Vergara (2005), separando a classificação das pesquisas em dois grupos: quanto aos objetivos e quanto aos procedimentos técnicos utilizados. Assim, o presente trabalho é de caráter exploratório e bibliográfico. Como procedimento técnico, uma pesquisa bibliográfica foi executada. O caráter exploratório do trabalho justifica-se, pois, por meio desta abordagem, o pesquisador é provido de conhecimentos diversos a respeito do assunto em estudo, tendo como "objetivo proporcionar maior familiaridade com o problema, com vistas a torná-lo mais explícito ou construir hipóteses" (GIL, 2002, p. 41).

A pesquisa é também classificada como bibliográfica pela procura de informações em livros e artigos e pode ainda ser caracterizada como uma análise teórico sistemática, pois visou identificar os estudos na área de design de novos produtos e serviços, gestão do design e modelos de negócio. Para isso, foi feita uma seleção de livros e artigos nacionais e internacionais que estavam relacionados à economia criativa aplicada aos modelos de negócios, com particular interesse naqueles criados em rede no contexto da Internet e que tiveram a possibilidade da colaboração entre todos os agentes envolvidos. Posteriormente, foram estudados os conceitos do quadro de proposta de valor (OSTERWALDER et al, 2015) que poderiam indicar formas e considerações na aplicação desse modelo de gestão ao design desses tipos de novos modelos de negócios criados no contexto da Internet.

\subsection{Etapas da pesquisa e processo de escolha das palavras-chave da pesquisa}

Antes de iniciar a pesquisa sistemática (Quadro 1 e Quadro 2), foi realizado um processo exploratório das palavras e a combinação das mesmas apenas nos últimos cinco anos de publicação (2010-2015) no site do Google acadêmico. Em português, as palavras escolhidas foram: “ (economia criativa) AND (canvas proposta de valor)", que geraram 198 publicações. Já os termos pesquisados em inglês foram: " (creative economy) AND (canvas value proposition design)", que geraram 12.300 publicações. A respeito da pesquisa sistêmica (Quadro 1 e Quadro 2) em bases de dados acadêmicos, foi desenvolvida em duas etapas, com os critérios de filtragem. 
Quadro1 - Etapa 1.1 da pesquisa sistêmica

\begin{tabular}{|c|c|c|c|}
\hline $\begin{array}{c}\text { Anos de } \\
\text { publicação }\end{array}$ & Termos & Bases de dados & $\begin{array}{l}\text { Número de } \\
\text { publicações }\end{array}$ \\
\hline todos & $\begin{array}{l}\text { (economia criativa) AND } \\
\text { (canvas proposta de } \\
\text { valor) }\end{array}$ & $\begin{array}{l}\text { SciELO - Scientific Electronic Library Online } \\
\text { Site: scielo.org }\end{array}$ & (0) \\
\hline todos & $\begin{array}{l}\text { (economia criativa) AND } \\
\text { (canvas proposta de } \\
\text { valor) }\end{array}$ & $\begin{array}{l}\text { Periódicos capes } \\
\text { Site: www.periodicos.capes.gov.br }\end{array}$ & (0) \\
\hline 2010-2015 & $\begin{array}{l}\text { (creative economy) and } \\
\text { (canvas value proposition } \\
\text { design) }\end{array}$ & $\begin{array}{l}\text { SCIENCEDIRECT }{ }^{\circledR} \\
\text { Site: www.sciencedirect.com }\end{array}$ & (32) \\
\hline 2010-2015 & $\begin{array}{l}\text { (creative economy) AND } \\
\text { (canvas value proposition } \\
\text { design) }\end{array}$ & $\begin{array}{l}\text { Scopus } \\
\text { Site: www.scopus.com }\end{array}$ & (1) \\
\hline 2010-2015 & $\begin{array}{l}\text { (creative economy) AND } \\
\text { (canvas value proposition } \\
\text { design) }\end{array}$ & $\begin{array}{l}\text { Springer } \\
\text { Site:www.link.springer.com }\end{array}$ & (59) \\
\hline
\end{tabular}

Fonte: Dados da pesquisa (2015).

Quadro 2 - Etapa 1.2 da pesquisa sistêmica

\begin{tabular}{|c|c|c|c|}
\hline $\begin{array}{c}\text { Anos de } \\
\text { publicação }\end{array}$ & Bases de dados & Filtros & $\begin{array}{l}\text { Número de } \\
\text { publicações }\end{array}$ \\
\hline \multirow{3}{*}{ 2010-2015 } & \multirow{3}{*}{ SCIENCEDIRECT ${ }^{\oplus}$} & TERMOS USADOS NA BUSCA & \\
\hline & & $\begin{array}{l}\text { creative economy canvas value proposition design } \\
\text { business model generation }\end{array}$ & (30) \\
\hline & & $\begin{array}{l}\text { Artigos descartados por falta de relação com o } \\
\text { foco da pesquisa }\end{array}$ & $(-29)$ \\
\hline 2010-2015 & Scopus ${ }^{\circledast}$ & $\begin{array}{l}\text { Artigo duplicado, está incluído nos resultados da } \\
\text { Springer }\end{array}$ & (0) \\
\hline \multirow{3}{*}{ 2010-2015 } & \multirow{3}{*}{ Springer ${ }^{\circledR}$} & TERMOS USADOS NA BUSCA & \\
\hline & & $\begin{array}{l}\text { (creative economy AND canvas value proposition } \\
\text { design) (business model generation) }\end{array}$ & (6) \\
\hline & & Apenas artigos de livre acesso & $(-6)$ \\
\hline & & $\begin{array}{l}\text { Publicações com conteúdo relevante no } \\
\text { objetivo da pesquisa }\end{array}$ & (1) \\
\hline
\end{tabular}

Por causa da falta de resultados nas bases de dados Scielo e Periódicos Capes, que poderiam dar uma perspectiva mais abrangente do estado da economia criativa brasileira, decidiu-se por realizar uma segunda procura com os termos: "(economia) AND (criativa)", no período de publicação entre os anos 2010 e 2015, e cujos resultados podem ser vistos no Quadro 3.

Quadro 3 - Etapa 2 da pesquisa sistêmica

\begin{tabular}{|c|l|l|c|}
\hline $\begin{array}{c}\text { Anos de } \\
\text { publicação }\end{array}$ & \multicolumn{1}{|c|}{ Termos } & \multicolumn{1}{|c|}{ Bases de dados } & $\begin{array}{c}\text { Número de } \\
\text { publicações }\end{array}$ \\
\hline $2010-2015$ & $\begin{array}{l}\text { (economia) AND } \\
\text { (criativa) }\end{array}$ & $\begin{array}{l}\text { SciELO - Scientific Electronic Library Online } \\
\text { Site: scielo.org }\end{array}$ & (7) \\
\hline $2010-2015$ & $\begin{array}{l}\text { (economia) AND } \\
\text { (criativa) }\end{array}$ & $\begin{array}{l}\text { Periódicos capes } \\
\text { Site: www.periodicos.capes.gov.br }\end{array}$ & (176) \\
\hline
\end{tabular}


Fonte: Dados da pesquisa (2015).

Segundo as possibilidades de filtragem das bases de dados, foram incluídos novos termos (Quadro 4) e, junto ao foco da pesquisa (Quadro 5), os resultados são mostrados nos quadros cinco e seis.

Quadro 4 - Etapa 2.2 da pesquisa sistêmica

\begin{tabular}{|c|l|l|c|}
\hline $\begin{array}{c}\text { Anos de } \\
\text { publicação }\end{array}$ & \multicolumn{1}{|c|}{ Termos } & \multicolumn{1}{|c|}{ Bases de dados } & $\begin{array}{c}\text { Número de } \\
\text { publicações }\end{array}$ \\
\hline $2010-2015$ & $\begin{array}{l}\text { (economia) AND } \\
\text { (criativa) (Brasil) }\end{array}$ & $\begin{array}{l}\text { SciELO - Scientific Electronic Library Online } \\
\text { Site: scielo.org }\end{array}$ & (11) \\
\hline $2010-2015$ & $\begin{array}{l}\text { (economia criativa) } \\
\text { AND (Internet) AND } \\
\text { (Inovação) AND (Brasil) }\end{array}$ & $\begin{array}{l}\text { Periódicos capes } \\
\text { Site: www.periodicos.capes.gov.br }\end{array}$ & (20) \\
\hline
\end{tabular}

Fonte: Dados da pesquisa (2015).

Quadro 5 - Etapa 2.2 da pesquisa sistêmica

\begin{tabular}{|c|l|c|}
\hline $\begin{array}{c}\text { Anos de } \\
\text { publicação }\end{array}$ & \multicolumn{1}{|c|}{ Bases de dados } & Publicações relevantes segundo o foco da pesquisa \\
\hline $2010-2015$ & SciELO & (2) \\
\hline $2010-2015$ & Periódicos capes & $\begin{array}{l}\text { Total de Publicações } \\
\text { com conteúdo relevante } \\
\text { para o foco da pesquisa }\end{array}$ \\
\cline { 2 - 3 }
\end{tabular}

Fonte: Dados da pesquisa (2015).

\section{ANÁLISE E DISCUSSÃO DE RESULTADOS}

A proposta de valor refere-se ao conjunto de produtos e serviços que geram valor a um determinado segmento de clientes, satisfazendo suas necessidades. Esses valores podem ser quantitativos (preço, agilidade na entrega) ou qualitativos (experiência de compra, comodidade) (LANDT; DAMSTRUP, 2013). Cada proposição de valor é composta de um conjunto selecionado de produtos e serviços que atende às exigências de um segmento de clientes, visando a satisfazer suas necessidades particulares. É a oferta da empresa para os seus clientes, com características adicionais, atributos e agregada de benefícios (OROFINO, 2011; OSTERWALDER, 2004).

De acordo com Osterwalder e Pigneur (2010), as propostas de valor podem ser norteadas por um conjunto de características e atributos que visam agregar valor à oferta da proposta por parte da empresa: novidades, performance, customização, realização do trabalho, marca, preço, redução de custos, redução de riscos, acessibilidade e conveniência, sendo usadas como ferramenta de diagnóstico, de pesquisa e de estado da empresa. Segundo Brown (2010), uma visão da inovação é menos sustentável hoje do que nunca, e uma filosofia de gestão baseada apenas na seleção de uma entre várias estratégias existentes será superada por novos avanços. Destaca o autor, no entanto, que é preciso ter uma abordagem em que a inovação seja poderosa, eficaz e amplamente acessível, que possa ser integrada a todos os aspectos dos negócios da sociedade e que indivíduos e equipes possam utilizá-la para gerar ideias inovadoras que sejam implementadas e que, portanto, façam a diferença (BROWN, 2010).

A seguir, no Quadro 6, apresenta-se a relação das dez empresas configuradas entre as dez gestões mais criativas do Brasil, segundo a pesquisa divulgada pela Revista Exame, bem como a operacionalização da gestão que contemplou a inserção na lista de gestão capacitada pela criatividade (AYRES, 2012). 
Quadro 6 - Relação das empresas listadas

\begin{tabular}{|c|c|}
\hline Lista das Empresas & Fatores Determinantes \\
\hline UNILEVER & $\begin{array}{l}\text { A Unilever elegeu a inovação como prioridade há algum tempo. Desde } \\
2001 \text {, por exemplo, a empresa fechou uma parceria com o Pão de Açúcar } \\
\text { para instalar pontos de coleta de recicláveis nos supermercados da rede. } \\
\text { A companhia também lançou versões concentradas de produtos como } \\
\text { o amaciante Comfort, com o intuito de diminuir o impacto ambiental } \\
\text { envolvido na sua produção. }\end{array}$ \\
\hline $3 \mathrm{M}$ & $\begin{array}{l}\text { Os negócios da 3M são naturalmente associados à inovação: das mesas de } \\
\text { seus cientistas nasceram criações como o lendário post-it. Hoje, a empresa } \\
\text { também busca expandir o fornecimento de tecnologias para o setor de } \\
\text { energia. }\end{array}$ \\
\hline IBM & $\begin{array}{l}\text { A IBM consolidou sua presença no setor de tecnologia da informação } \\
\text { no país. A aquisição vai ao encontro da estratégia da IBM mundo afora. } \\
\text { Em 2004, a companhia abandonou os negócios de PC para investir em } \\
\text { consultoria e serviços, elegendo a divisão de softwares como seu principal } \\
\text { negócio. Daqui para frente, um centro de pesquisa e desenvolvimento } \\
\text { deverá ser criado de olho nos setores de recursos naturais e infraestrutura. }\end{array}$ \\
\hline GENERAL ELECTRIC & $\begin{array}{l}\text { A empresa terá como investimento principal a construção de um centro } \\
\text { de pesquisas no Rio de Janeiro. }\end{array}$ \\
\hline TELEFÔNICA & $\begin{array}{l}\text { A empresa tem como princípio investimentos pesados na criação de } \\
\text { tecnologias de ponta. }\end{array}$ \\
\hline AMBEV & Sua cultura é fundamentalmente baseada na inovação de seus produtos. \\
\hline PETROBRÁS & $\begin{array}{l}\text { A Petrobras é reconhecida pelo engajamento em propostas de inovação. } \\
\text { Na Rio+20, a empresa apresentou a tecnologia de etanol com o bagaço } \\
\text { da cana, que permite a ampliação da produção em até } 40 \% \text { sem danos à } \\
\text { natureza. }\end{array}$ \\
\hline ITAÚ & $\begin{array}{l}\text { Primeiro banco a aparecer no ranking, o Itaú é adepto do chamado } \\
\text { design thinking. Em um espaço de } 205 \text { metros quadrados na sede do } \\
\text { banco em São Paulo, as equipes de desenvolvimento de produtos se } \\
\text { reúnem armadas de bloquinhos e canetas coloridas com o intuito de criar } \\
\text { produtos e debater ideias. }\end{array}$ \\
\hline SANTANDER & $\begin{array}{l}\text { Na nona posição entre as companhias com gestão mais inovadora, o } \\
\text { Santander fundamenta sua gestão em princípios de sustentabilidade. }\end{array}$ \\
\hline PEPSICO & $\begin{array}{l}\text { Além da preocupação em lançar versões diferentes de um mesmo } \\
\text { produto, outra preocupação da companhia é sempre desenvolver } \\
\text { produtos politicamente corretos. }\end{array}$ \\
\hline
\end{tabular}
Fonte: Ayres (2012)

Esses dados mostram grandes empresas e multinacionais. No entanto, já começam a surgir pequenos negócios no Brasil que acreditam numa gestão com base nos princípios norteadores, características e potencialidades da economia criativa, que foram descritos no início do artigo. Ainda hoje, as empresas com uma grande capacidade de recursos, como as mostradas no Quadro 6, desconsideram os princípios norteadores de diversidade cultural e inclusão social ou não acreditam realmente que possam ter um impacto suficientemente positivo para colocá-los como prioridades em suas linhas estratégicas de ação global. As grandes empresas olham mais para os princípios norteadores de sustentabilidade e a inovação em suas propostas de valor para seus segmentos de clientes. No entanto, algumas delas valorizam potencialidades e características da economia criativa como a produção não poluente e a inovação tecnológica.

\section{CONCLUSÕES E ESTUDOS FUTUROS}

O conceito de economia criativa teve origem no termo "indústria criativa". O conceito de indústria criativa nasceu como inspiração do projeto Creative Nation, do governo australiano, em 1994, para definir a importância do trabalho criativo, identificar a sua contribuição para a economia e definir o papel das tecnologias como aliadas da política cultural. Posteriormente, foi estabelecido pelo governo do Reino Unido, em 1997, pela 
necessidade de se analisar as contas nacionais, as tendências de mercado e as vantagens competitivas que o país poderia ter. Identificando-se, nesse exercício, treze setores de maior potencial, que hoje são chamados de indústrias criativas e referem-se à atividade empresarial que gera valor econômico através de conteúdo de origem cultural. Essas indústrias criativas, no Brasil, apesar da existência de modelos produtivos diversos conviventes no tempo e no espaço, como foi explicado antes, apresentam uma estimativa de participação do PIB Criativo, em relação ao PIB Total (2004-2013), que passa de 2,09\%, em 2004, para 2,60\%, em 2013.

O SEBRAE, com base nesses dados, coloca como desafio a necessidade de tornar os negócios criativos, sustentáveis, posto que os agentes que atuam no mercado dos negócios criativos no Brasil ainda precisam desenvolver a sustentabilidade de seus empreendimentos, adquirir independência dos recursos do Estado, profissionalizar a gestão e buscar a longevidade de seus negócios. De modo que resulta imperioso, portanto, estimular modelos inovadores para o desenvolvimento da economia criativa brasileira.

O ciclo de desenvolvimento de um modelo de negócios é a maneira como uma organização cria, entrega e captura valor. Em ambientes instáveis e carregados de incerteza, os modelos de negócios bem projetados e inovadores podem desempenhar papel crucial, realizando a ligação entre estratégia, processos internos e sistemas de informação, simplificando a comunicação entre esses componentes e favorecendo a difusão do conhecimento interno, o que por sua vez acaba gerando vantagem competitiva.

As empresas de economia criativa estão inseridas no terceiro setor, que trata de bens e serviços baseados em símbolos e imagens, e refere-se ao conjunto de atividades fundamentadas na criatividade ou mesmo na habilidade individual cognitiva e cujos produtos incorporam propriedade intelectual abrangendo as complexas cadeias produtivas culturais.

Assim, a proposta de valor procura resolver os problemas do cliente e satisfazer suas necessidades, baseando-se nos princípios norteadores, características e potencialidades da economia criativa. De modo que cada proposta de valor criará valor para um segmento de cliente com uma combinação de elementos direcionados especificamente àquele segmento. E o uso do quadro de proposta de valor como ferramenta resultará ótimo para analisar, planejar, sintetizar e criar diferenciais nos bens e serviços da economia criativa, direcionando-os especificamente àquele segmento.

Finalmente, a respeito de pesquisas futuras, o estudo das propostas de valor das áreas criativas e dos segmentos criativos no Brasil, em relação aos segmentos de cliente aos quais estão direcionados, resultaria interessante na tentativa de fazer uma avaliação na busca por linhas de ação que melhorem o ajuste dos princípios norteadores, características e potencialidades da economia criativa no país.

\title{
CREATIVE ECONOMY AS VALUE PROPOSAL IN BUSINESS MODELS
}

\begin{abstract}
The creative economy focuses on the individual and the collective potential to produce creative goods and services. In particular, the creative economy focuses on activities based on knowledge and producing tangible, intangible, intellectual and artistic goods with creative content and economic value. Therefore, business models and management stem from activities, products or services developed from knowledge, creativity, and intellectual capital of individuals with a view to generate employment and income. The article presents a systematic literature of exploratory research about the creative economy, creative industries, and creative goods and services in Brazil. Furthermore, it shows the relationship between a business model framework concept and new forms of business in the creative economy. Additionally it brings arguments and reflections about the planning needs of research and innovation to achieve a proactive attitude in business and thus cope with the changes and transitions of the production system.
\end{abstract}

Keywords: Creative economy. Value proposition canvas. Business model. Design thinking.

\section{REFERÊNCIAS}

AYRES, M. As 10 empresas mais criativas em gestão do Brasil. [2012]. Disponível em: <http://exame.abril. com.br/gestao/noticias/as-10-empresas-mais-criativas-em-gestao-do-brasil>. Acesso em: 2 jun. 2016.

BROWN, T. Design Thinking: uma metodologia poderosa para decretar o fim das velhas ideias. Rio de Janeiro: Elsevier, 2010.

BOLTANSKI, L.; CHIAPELLO, E. El nuevo espíritu del capitalismo. Madri: Ediciones Akal, 2002. v. 13. 
Francisco Gómez Castro; Luiz Fernando Figueiredo

BRASIL. Ministério da Cultura. Plano da Secretaria da Economia Criativa-Políticas, diretrizes e ações 2011 a 2014. [2011]. Disponível em: <http://www2.cultura.gov.br/site/wpcontent/uploads/2012/08/livro_web2edicao.pdf >. Acesso em: 5 maio 2015.

BUETTGEN, J. J.; FREDER, S. M. Indústrias Criativas: o lugar em que criatividade gera valor In: BUETTGEN, J. J.; FREDER, S. M. (Org.). Economia Criativa: Inovação, Cultura, Tecnologia e Desenvolvimento. Curitiba: Juruá Editora, 2015. p. 107-116.

CASTELLS, M. A sociedade em rede. 9. ed. São Paulo: Paz e Terra, 2006.

CONFERÊNCIA DAS NAÇÕES UNIDAS SOBRE COMÉRCIO E DESENVOLVIMENTO (UNCTAD). Relatório de Economia Criativa 2010: Economia criativa: Uma opção de Desenvolvimento Viável. [2010] Disponível em: <http://www2.cultura.gov.br/economiacriativa/wpcontent/uploads/2013/06/relatorioUNCTAD2010Port.pdf $>$. Acesso em: 4 jun. 2015.

FEDERAÇÃO DAS INDÚSTRIAS DO RIO DE JANEIRO (FIRJAN). Mapeamento da Indústria Criativa no Brasil. [2014]. Disponível em: <http://www.firjan.org.br/economiacriativa/pages/default.aspx>. Acesso em: 4 jun. 2015.

GIL, A. C. Como elaborar projetos de pesquisa. São Paulo: Atlas, 2002.

GORZ, A.; IMATERIAL, O. Conhecimento, valor e capital. São Paulo: Annablume, 2005.

HOWKINS, J. The creative economy: How people make money from ideas. UK: Penguin, 2002.

HARVEY, D.; SOBRAL, A. U. Condição pós-moderna. São Paulo: Edições Loyola, 1994.

LANDT, M.; DAMSTRUP, M. V. Innovation adoption's effect on established business models as means to adjust in a rapid changing technological and innovative landscape: A case study on Business Models, innovation Hype Cycles and the street process for adopting innovations. 2013. Dissertação (Mestrado) - Copenhagen Business School, Copenhagen, Dinamarca.

MAFFESOLI, M. Sobre o nomadismo: vagabundagens pós-modernas. Rio de Janeiro: Record, 2001.

MIGUEZ, P. Economia criativa: uma discussão preliminar. In: NUSSBAUMER, G.M. (Org.). Teorias e políticas da cultura: visões multidisciplinares. Salvador: EDUFBA, 2007. p. 95-114.

OLIVEIRA, J. M. D.; ARAUJO, B. C. D.; SILVA, L. V. Panorama da economia criativa no Brasil. [2013]. Disponível em: <http://www.ipea.gov.br/portal/images/stories/PDFs/TDs/td_1880.pdf >. Acesso em: 5 maio 2015.

OROFINO, M. A. R. Técnicas de criação do conhecimento no desenvolvimento de modelos de negócio. 2011. Dissertação (Mestrado em Engenharia e Gestão do Conhecimento) - Universidade Federal de Santa Catarina, Florianópolis, 2011.

OSTERWALDER, A. The business model ontology: A proposition in a design science approach. 2004. Tese (Doutorado) - Université de Lausanne, Lausanne, Switzerland.

OSTERWALDER, A.; PIGNEUR, Y. Business model generation: a handbook for visionaries, game changers, and challengers. New York: John Wiley \& Sons, 2010.

OSTERWALDER, A. et al. Value Proposition Design: How to Create Products and Services Customers Want. New York: John Wiley \& Sons, 2015.

REIS, A. C. F. Economia criativa como estratégia de desenvolvimento: uma visão dos países em desenvolvimento. São Paulo: Garimpo Soluções; Itaú Cultural, 2008. 
SERVIÇO BRASILEIRO DE APOIO ÀS MICRO E PEQUENAS EMPRESAS (SEBRAE). Termo de referência de economia criativa. [2012]. Disponível em: <http://www.bibliotecas.sebrae.com.br/chronus/ARQUIVOS_CHRONUS/ bds/bds.nsf/17d34b0fadf21eb375cb775f04a9249b/\$File/4567.pdf>. Acesso em: 4 jun. 2015.

SERVIÇO BRASILEIRO DE APOIO ÀS MICRO E PEQUENAS EMPRESAS. O que é Economia Criativa. [2015]. Disponível em: <http://www.sebrae.com.br/sites/PortalSebrae/artigos/O-que-é-Economia-Criativa >. Acesso em: 5 maio 2015.

VERGARA, S. C. Métodos de Pesquisa em Administração. São Paulo: Atlas, 2005.

VICKERY, J. Creative Economy Report 2013 Special Edition: widening local development pathways. Cultural Trends, v. 24, n. 2, p. 189-193, 2013. Disponível em: <http://www.unesco.org/culture/pdf/creative-economy-report-2013.pdf>. Acesso em: 5 maio 2015.

VIRNO, P. Grammatica della moltitudine: Per una analisi delle forme di vita contemporanee. Itália: Derive Approdi, 2001. 